Pak. J. Agri. Sci., Vol. 53(1), 1-6; 2016

ISSN (Print) 0552-9034, ISSN (Online) 2076-0906

DOI: $10.21162 / P A K J A S / 16.4717$

http://www.pakjas.com.pk

\title{
EFFECTS OF 5-AZACYTIDINE AND GIBBERELLIC ACID ON FLOWER DEVELOPMENT OF AZALEA
}

\author{
Hong Zhou ${ }^{1, \uparrow}$, Jin Liao ${ }^{2, \uparrow}$, Bing Liu ${ }^{1}$, Sha Cao ${ }^{1}$, Muhammad Azam³ and Yiping Xia ${ }^{1, *}$ \\ ${ }^{1}$ Department of Horticulture, College of Agriculture and Biotechnology, Zhejiang University, Hangzhou, P.R. China; \\ ${ }^{2}$ Zhejiang Humanities Landscape Co., Ltd., Hangzhou, P.R. China; ${ }^{3}$ Institute of Horticultural Sciences, University of \\ Agriculture, Faisalabad, Pakistan. \\ These authors contributed equally in this paper. \\ *Corresponding author's e-mail: lilyzhou@zju.edu.cn; ypxia@zju.edu.cn
}

\begin{abstract}
Azalea is one of the most popular ornamental plants in China. On the production of pot azaleas, heating strategy is widely used to force flowering, so the products can meet the needs of Spring Festival market in China. This study was conducted to find another possible way to break flower bud dormancy and promote anthesis through environment friendly ways. Fouryear-old azalea 'Hong Shanhu' (Chinese azalea cultivar) were sprayed with different combinations of 5-azacytidine (2.5, 10, 40 and $\left.160 \mathrm{mg} \mathrm{L}^{-1}\right)$ and gibberellic acid $\left(300 \mathrm{mg} \mathrm{L}^{-1}\right)$. These were kept in greenhouse during the winter with no extra heating device. Morphological changes, endogenous hormones, and the degree of DNA methylation were recorded. The results showed that the combination of $40 \mathrm{mg} \mathrm{L}^{-1} 5$-azaC and $300 \mathrm{mg} \mathrm{L}^{-1} \mathrm{GA}_{3}$ can highly promote flower bud growth and brought anthesis 17 days earlier than controls. IAA content increased about twofold (control and T1) and fivefold (T4) after growing for four months. A steep decrease of DNA methylation was observed from November to February and followed by an increase until flowering in all treatments. The foliar application of these chemicals was found to be more effective on bud dormancy breaking by DNA demethylation and decrease of ABA levels.
\end{abstract}

Keywords: Rhododendron, dormancy, methylation, plant growth regulator, epigenetics, abscisic acid.

\section{INTRODUCTION}

Azaleas are among the most important ornamental shrubs in Europe (Scariot, 2007), America and East Asia, which contain thousands of cultivars with various flower morphotypes and flowering patterns. In China, it could be chased back to the Tang Dynasty when our ancestors started to enjoy its beauty (Zhou, 2013a). Nowadays, the areas of commercial production for azaleas have been expanded to more than 2500 hectares in China and over 350 million cuttings are propagated every year to meet the needs of landscaping and home cultivation (Zhou, 2010). In natural conditions, flower buds of azalea enter dormancy in winter to overcome the low temperature and usually bloom in April to May (Meijon, 2009). However, almost $80 \%$ to $85 \%$ floral products are sold during the Chinese New Year (Wang, 2014), which is mainly in January or February, the coldest month in a year. Thus, it is crucial to regulate the timing of flowering in azalea.

It has been studied previously to find various ways to regulate dormancy and bud break by using different chemicals in the last few decades (Arora, 2003). Among these chemicals, gibberellic acid (GA) applications were proved to be efficient on dormancy-breaking by partly substituting the cold requirements in azaleas and other woody plants (Bodson, 1986; Chang and Sung, 2000; Yeo et al., 2012; Christiaens et al., 2012).

It is also reported that DNA demethylation is involved during vernalization (Demeulemeester, 1999). The usage of 5-azacytidine (5-azaC) could lower the DNA methylation level by merging analogue in place of cytosine (Jones, 1985) and inhibiting the action of methyltransferase enzyme (Bouchard, 1983). In Burn's (1993) experiment, Arabidopsis thaliana and Thlaspi arvense treated with 5-azaC turned up with an early flowering on nonvernalized plants, just reacted the same as those treated with cold. In some short-day plants, DNA demethylation caused by 5 -azaC could also induce flowering (Kondo, 2006, 2007, 2010). As far as our understanding, 5-azaC has never been used to manipulate flowering in azaleas.

In China, on a regular basis, flowering of azaleas is usually forced by temperature control (high temperature) or photoperiod manipulation. When the flower buds become dormant, only be released if their chilling requirements are satisfied (Christiaens, 2015). In view of global warming and expansive costs, cold storage is hard to accomplish in most of the production areas. We tried different combinations of 5-azaC and $\mathrm{GA}_{3}$ in this study to 1) document the morphological changes and flowering patterns of azalea under different treatments; 2) evaluate the effect of each treatment on promoting flowering; 3) analyze the endogenous hormones and global DNA methylation during 
Zhou, Liao, Liu, Cao, Azam \& Xia

Table 1. Treatments applied to 'Hong Shanhu' to promote flowering.

\begin{tabular}{lcccccccccc}
\hline & \multicolumn{10}{c}{ Treatments } \\
\cline { 2 - 13 } & Control & T1 & T2 & T3 & T4 & T5 & T6 & T7 & T8 & T9 \\
\hline $\mathrm{GA}_{3}\left(\mathrm{mg} \mathrm{L}^{-1}\right)$ & 0 & 300 & 300 & 300 & 300 & 300 & 0 & 0 & 0 & 0 \\
$5-\mathrm{azaC}\left(\mathrm{mg} \mathrm{L}^{-1}\right)$ & 0 & 0 & 2.5 & 10 & 40 & 160 & 2.5 & 10 & 40 & 160 \\
\hline
\end{tabular}

floral development.

\section{MATERIALS AND METHODS}

Plant materials: A late-flowering azalea cultivar 'Hong Shanhu' was used in the experiments supplied by Weitang azalea garden (Jiashan, China). Root cuttings grown outside for four years under standard water and fertilizer management, then were transplanted into one-gallon pots containing peat, pine needles and yellow clay $(3: 1: 1$ by volume) and placed in experiment fields belonging to Zhejiang University in Hangzhou $\left(120^{\circ} 11^{\prime} \mathrm{E}, 30^{\circ} 16^{\prime} \mathrm{N}\right)$ (China) at a planting density of nine plants per meter square. Experimental set-up: One hundred plants were subjected to different combinations of 5-azacytidine (5-azaC) and $\mathrm{GA}_{3}$, as shown in Table 1. A surfactant (Tween-20) at $0.05 \%$ was added to each solution. The control plants were sprayed with tap water. The first spray started on 15th November and followed by two more sprays once a week. All the plants were kept outside under natural conditions until 26th December and moved into a greenhouse till blooming with an average temperature above $16^{\circ} \mathrm{C}$. Sampling dates for endogenous PGRs analysis and global DNA methylation were selected at least monthly to cover the different stages of flower bud development. In every sampling, three to five apical buds were randomly taken from one plant as one replicate, for a total of five replicates per treatment. All the samples were quick-frozen by liquid nitrogen immediately, and stored at $-80^{\circ} \mathrm{C}$ until extraction.

Observations and measurements: Ten flower buds were randomly picked from each treatment to record the length (L) and diameter (D) every two weeks and their volume were estimated using the following formula:

$\mathrm{V}=1 / 3 \pi(\mathrm{D} / 2)^{2} \mathrm{~L}$

Mark the dates of the buds showing color and anthesis in each treatment. Calculating the necessary growing degree day (GDD) for the plants to bloom using Meijon's method (Meijon, 2011).

Analysis of PGRs: The endogenous plant growth regulators (PGRs) including abscisic acid (ABA), indole acetic acid (IAA) and GA were analyzed from $300 \mathrm{mg}$ buds (frozen weight) using enzyme-linked immunosorbent assay (ELISA) kits for hormones (China Agricultural University, China). The extraction, purification and determination of PGRs were performed as described by Hao (2001).
Determination of global DNA methylation: Genomic DNA was extracted from $200 \mathrm{mg}$ dried frozen buds and purified as described by Zhou (2013b). DNA concentration and quality were determined by electrophoresis and spectrophotometry. Approximately $3 \mu \mathrm{g}$ DNA was hydrolyzed according to Demeulemeester (1999). After filtered through a $0.45 \mu \mathrm{m}$ filter membrane, the total hydrolysate was analyzed on an HPLC system (Agilent 1100, USA) with a Hypersil BDS C18 column $(4.6 \times 250 \mathrm{~mm}$, particle size $5 \mu \mathrm{m}$, Thermo Fisher, USA) operating at $30^{\circ} \mathrm{C}$. The mobile phase consisted of a special solvent (containing $6.25 \mathrm{mM}$ sodium pentanesulfonate, $0.1 \%$ triethylamine and $0.4 \%$ acetic acid) and methanol in the ratio 20:80 (v/v). The flow rate was set to $1 \mathrm{~mL} \mathrm{~min}{ }^{-1}$ with an injection volume of $20 \mu \mathrm{L}$. The detection was carried out at $273 \mathrm{~nm}$ using cytosine and 5methylcytosine (5mC) (Alfa Aesar, USA) as standard. Global DNA methylation was determined by the percentage of $5 \mathrm{mC}$ (concentration of $5 \mathrm{mC} \times 100 /$ (concentration of $5 \mathrm{mC}$ + concentration of cytosine)).

Statistical analysis: The data were analyzed using SPSS 20.0 software package. The volume of flower buds were subjected to a one-way ANOVA based on dates. For the contents of endogenous hormones, one-way ANOVA analysis was performed both by dates and treatments. The significance level was set to $\alpha=0.05$ for all the tests.

\section{RESULTS}

Effects of different treatments on flower development: Despite we collected the flower buds growth data every two weeks, to get a clear view of the difference between treatments, the results were summarized monthly (Table 2). The last measurement was set at March $5^{\text {th }} 2012$ due to the trend of blooming. All buds became bigger in the first month of treatment. But during the second month, all the other treatments and control plants hardly showed any increase in flower bud volume except for these in T4. After January 15th, buds in all treatments continued to grow. In the whole flower developing period, buds in T4 (sprayed with $300 \mathrm{mg}$ $\mathrm{L}^{-1} \mathrm{GA}_{3}$ and $40 \mathrm{mg} \mathrm{L}^{-1}$ 5-azaC) grew fastest and ended with the largest volume comparing to the rest. As to the effects between different kinds of chemicals, buds sprayed with both $\mathrm{GA}_{3}$ and 5-azaC were larger than those sprayed only with 5-azaC.

Start dates of buds showing color and blooming are the most direct evidence to evaluate the effects of different chemicals when forcing flowering. Buds in T4 were the earliest to 
Flower development in azalea

Table 2. Volume of flower buds measured monthly under different treatments.

\begin{tabular}{llllll}
\hline & \multicolumn{5}{c}{ Flower bud volume $\left(\mathbf{m m}^{3}\right)$} \\
\cline { 2 - 6 } & \multicolumn{1}{c}{ 15 Nov. } & \multicolumn{1}{c}{ 15 Dec. } & \multicolumn{1}{c}{ 15 Jan. } & \multicolumn{1}{c}{$\mathbf{1 4 ~ F e b .}$} & \multicolumn{1}{c}{ Mar. } \\
\hline Control & $87.60 \pm 12.20 \mathrm{a}$ & $126.02 \pm 18.89 \mathrm{a}$ & $114.73 \pm 17.18 \mathrm{~b}$ & $137.07 \pm 18.33 \mathrm{c}$ & $188.20 \pm 22.58 \mathrm{e}$ \\
T1 $^{\mathrm{a}}$ & $87.60 \pm 12.20 \mathrm{a}$ & $122.07 \pm 12.95 \mathrm{a}$ & $124.63 \pm 12.03 \mathrm{~b}$ & $218.04 \pm 44.78 \mathrm{ab}$ & $360.54 \pm 77.52 \mathrm{ab}$ \\
T2 & $87.60 \pm 12.20 \mathrm{a}$ & $127.83 \pm 13.20 \mathrm{a}$ & $131.65 \pm 15.36 \mathrm{ab}$ & $195.63 \pm 63.94 \mathrm{abc}$ & $316.90 \pm 69.56 \mathrm{bc}$ \\
T3 & $87.60 \pm 12.20 \mathrm{a}$ & $125.30 \pm 8.13 \mathrm{a}$ & $121.37 \pm 14.59 \mathrm{~b}$ & $186.31 \pm 51.13 \mathrm{bc}$ & $325.68 \pm 73.32 \mathrm{bc}$ \\
T4 & $87.60 \pm 12.20 \mathrm{a}$ & $129.56 \pm 18.74 \mathrm{a}$ & $150.16 \pm 35.47 \mathrm{a}$ & $256.13 \pm 81.50 \mathrm{a}$ & $410.18 \pm 56.64 \mathrm{a}$ \\
T5 & $87.60 \pm 12.20 \mathrm{a}$ & $118.70 \pm 10.83 \mathrm{a}$ & $132.70 \pm 13.68 \mathrm{ab}$ & $177.61 \pm 38.65 \mathrm{bc}$ & $343.19 \pm 79.65 \mathrm{abc}$ \\
T6 & $87.60 \pm 12.20 \mathrm{a}$ & $125.88 \pm 16.58 \mathrm{a}$ & $130.72 \pm 14.24 \mathrm{ab}$ & $147.21 \pm 47.46 \mathrm{bc}$ & $235.18 \pm 41.85 \mathrm{de}$ \\
T7 & $87.60 \pm 12.20 \mathrm{a}$ & $126.32 \pm 12.99 \mathrm{a}$ & $128.18 \pm 10.78 \mathrm{a}$ & $165.38 \pm 18.10 \mathrm{bc}$ & $276.39 \pm 54.94 \mathrm{~cd}$ \\
T8 & $87.60 \pm 12.20 \mathrm{a}$ & $114.66 \pm 17.64 \mathrm{a}$ & $124.36 \pm 18.46 \mathrm{a}$ & $160.19 \pm 47.54 \mathrm{bc}$ & $346.61 \pm 91.62 \mathrm{abc}$ \\
T9 & $87.60 \pm 12.20 \mathrm{a}$ & $123.59 \pm 11.01 \mathrm{a}$ & $124.23 \pm 12.12 \mathrm{a}$ & $174.09 \pm 70.18 \mathrm{bc}$ & $350.93 \pm 20.66 \mathrm{abc}$ \\
\hline
\end{tabular}

${ }^{a}$ for abbreviation of treatments please refer to Table 1 . Means $(n=10)$ and standard deviation followed by different letters are significantly different $(P=0.05$, Duncan's test) between treatments based on the same date.

Table 3. Start date of buds showing color, flowering and growing degree day in different treatments (Control, T1 and T4).

\begin{tabular}{llll}
\hline & Control & T1 $^{\mathbf{a}}$ & T4 \\
\hline Start date of buds showing color & $21 \mathrm{Mar}, 2012$ & $5 \mathrm{Mar}, 2012$ & $25 \mathrm{Feb}, 2012$ \\
Start date of flowering & $27 \mathrm{Mar}, 2012$ & $13 \mathrm{Mar}, 2012$ & $10 \mathrm{Mar}, 2012$ \\
Growing degree day & 1199 & 1038 & 1008 \\
\hline
\end{tabular}

${ }^{\mathrm{a}}$ for abbreviation of treatments please refer to Table 1.

show color and anthesis with an advance of 3 and 17 days as compared to the plants in $\mathrm{T} 1$ and control respectively (Table 3). Buds in T9 showed color 9 days later but bloomed at the same day as buds in T4 (results not listed here). It took the plants 14 days from showing color to start bloom in T4, while the time is shortened to 8 and 6 days in T1 and control. The later the buds showing color, the more quickly it bloomed (Table 3). In addition, the minimum temperature required for flowering under our experimental set-up was determined by growing degree day (GDD). It was observed that the controls needed to accumulate more GDD to bloom than plants with chemical treatments. We chose plants in T4 (with the best effect of bud break), control and T1 (only with $\mathrm{GA}_{3}$ ) to measure the changes of endogenous hormones and DNA methylation as the flower buds grow up.

Effects of 5-azaC and $\mathrm{GA}_{3}$ on endogenous hormones in flower buds: IAA content increased about twofold (control and T1) and fivefold (T4) after growing for four months (Fig.1a). In controls, it reached a minimum value on the second sampling and followed by a continuous growth. T4 triggered a violent increase of IAA content in flower buds immediately and significantly almost two times higher than in the buds of T1 and control except for the fifth sampling. Buds treated only with $\mathrm{GA}_{3}$ showed no significant difference on IAA content compared with controls except for the suddenly drop on 28th February. The ABA content peaked at 1st February and returned to the similar level as the beginning in all plants (Fig. 1b), especially for controls and buds from $\mathrm{T} 1$ the maximum content of $\mathrm{ABA}$ increased up to
$236.21 \%$ and $179.48 \%$ of its original value. However, ABA content increased only $13.55 \%$ at the top in $\mathrm{T} 4$ and remained almost extremely lower than in the other two groups. The ratio of IAA content to ABA content in buds rose about 7.6 times in $\mathrm{T} 4$, which was dramatically higher than in $\mathrm{T} 1$ and control (not shown in this Figure). The ratio change of GA content to ABA content (GA/ABA) during flower development showed a double peak figure (Fig. 1c). It increased up till January and dropped in February, and finally reached the top when the plants were about to bloom. The ratio change (GA/ABA) was found higher in $\mathrm{T} 4$ earlier than in $\mathrm{T} 1$ and control.

Effects of 5-azaC and $\mathrm{GA}_{3}$ on global DNA methylation: A steep decrease in the percentage of $5 \mathrm{mC}$ was observed from November to February and followed by an increase until flowering in all treatments (Fig. 1d). Plants sprayed with both 5-azaC and $\mathrm{GA}_{3}$ (T4) had the lowest level of DNA methylation and methylation were faster after the turning point in all treatments. After the flowering started, DNA methylation level decreased to normal at $13^{\text {th }}$ March (T4). While, it took longer for the plants in $\mathrm{T} 1$ and control to accomplish this process. Control plants were demethylated much slower than the others and the off-peak value occurred about one month later. However, the dynamics of methylation during flower development were similar for all treatments. 

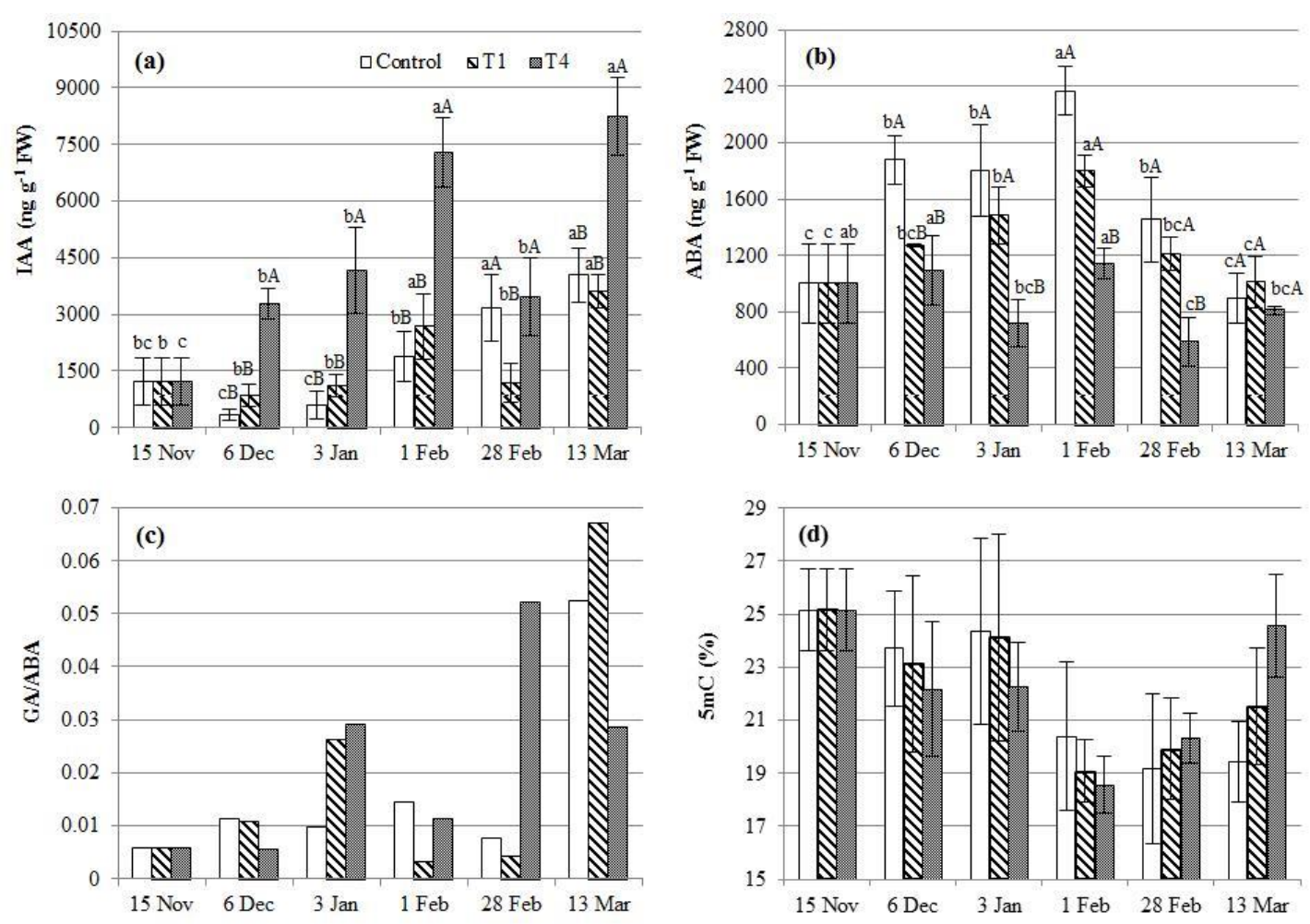

Figure 1. Changes of endogenous hormones and global DNA methylation in different treatments during the whole experimental period. (a) IAA content; (b) ABA content; (c) the ratio of GA content to ABA content; (d) global DNA methylation. The different lowercase letters indicate significant differences between dates within each treatment $(P \leq 0.05, \mathrm{n}=3)$, whereas, the different capital letters show significant differences between treatments within each date $(P \leq 0.05, \mathrm{n}=3)$ (for abbreviation of treatments refer to Table 1 ).

\section{DISCUSSION}

Bud dormancy is a complex biological problem. For the past century, much research has been published based on different aspects. The effects of chemicals on the initiation and development of flower buds could be totally opposite when treated at different stages of growth. Bodson (1986) found out that GA (4+7) could lead to a bud abortion when treatment applied at the time of floral transition. However, when the treatment was carried out on the inflorescence buds, it substituted for chilling in overcoming dormancy. It is speculated from the change of bud volume that buds were probably under dormant stage between December and January, so we sprayed the plants in the middle of November just when the dormancy was about to begin. Plants treated only with $300 \mathrm{mg} \mathrm{L}^{-1} \mathrm{GA}_{3}$ (T1) showed color of buds 16 days earlier and bloomed 14 days earlier than controls. Likewise, in Chang (2000) research, $500 \mathrm{mg} \mathrm{L}^{-1} \mathrm{GA}_{3}$ was used in the middle of dormancy (the end of December) and got a 10 or 9 days advancement on the blooming of two azalea species. The differences in blooming might be due to different concentrations of $\mathrm{GA}_{3}$, plant material and the start time of treatments. In our study, when treated with both $\mathrm{GA}_{3}$ and 5-azaC, the effects were incredibly good with a promotion of 25 and 17 days (of bud showing color and blooming, respectively) earlier than controls. We found it interesting that it took longer than controls for the treated plants to bloom since the buds started showing color. It may because the controls accumulated more GDD units than treatments (Meijon, 2011).

Abscisic acid (ABA) plays a crucial role in the establishment and maintenance of dormancy (Gotz, 2014). It was found in Camelia a clear downward trend of flower buds ABA levels as the cold treatment continued (Berruti, 2012). In our experiment, $\mathrm{GA}_{3}$ and 5 -azaC treatments both induced a lower level of ABA than controls. When the dormancy of flower buds was inhibited (mainly during February), the ABA content decreased. The correlation of endogenous hormones, DNA methylation and flower bud volume was also tested (Table 4). Both ABA content and ratio of GA to ABA were significantly related with flower bud volume. IAA and GA content seemed to be not so relevant with the bud growth. 
Flower development in azalea

Table 4. Correlation coefficients matrix for flower bud volume, endogenous hormones and DNA methylation.

\begin{tabular}{lcrrccc}
\hline & ABA & IAA & 5mC & Flower bud volume & GA/ABA & GA \\
\hline ABA & 1.000 & & & & & \\
IAA & $-0.525^{*}$ & 1.000 & & & & \\
5mC & -0.028 & -0.273 & 1.000 & & & \\
Flower bud volume & $-0.549^{*}$ & 0.462 & -0.149 & 1.000 & 1.000 & \\
GA/ABA & $-0.509^{*}$ & 0.314 & -0.085 & $0.593^{*}$ & $0.885^{* *}$ & 1.000 \\
GA & -0.114 & 0.114 & -0.014 & 0.410 & \\
\hline
\end{tabular}

* Significance at the 0.05 probability level; ** Significance at the 0.01 probability level.

Treating plants with the demethylating agent, 5-azaC, brought early flowering by demethylation of global DNA (Finnegan, 1998; Lizal, 2001; Brown, 2008). Meijon (2010) observed that on the floral transition of azalea, there is a sharp decrease of DNA methylation. When floral differentiation is completed, the degree of global DNA methylation keeps increasing till flowering (Meijon, 2011). The dynamics of DNA methylation during flower development in our study was a little different with Meijon's (2011) results. However, azalea cultivars used in Meijon' (2011) studies don't need to be vernalized during floral transition and anthesis. DNA methylated after flower buds formed. Whereas, the cultivar in our study has a clear requirement of cold storage to overcome dormancy. In the dormant stage, DNA demethylated in flower buds with different speed. The faster DNA methylated, the earlier the plant bloomed. All these indicated that the chilling requirement could partially be substituted by the applying 5azaC, but the effect might not be that obvious compared with $\mathrm{GA}_{3}$ treatment.

Conclusion: The use of both $\mathrm{GA}_{3}$ and 5-azaC with different combination has shown to break the early bud dormancy in azalea. The foliar application of these chemicals was more effective in the demethylation of DNA and decrease of ABA levels, and could partly substitute with chilling requirement. This encourages us to improve the time and concentration of chemical uses on flowering forcing, and may provide a well strategy for early breaking of flower bud dormancy of azalea plants for commercial production at the time of New Year in the country.

Acknowledgement: This research was supported by funds from the Science and Technology Major Project of Zhejiang Province, China (projects 2012C12909-7 and 2012LM202). The authors especially thank Yuan Jingqun from Analysis Center of Agrobiology and Environmental Sciences \& Institute of Agrobiology and Environmental Sciences, Zhejiang University for the help on HPLC analysis of DNA methylation.

\section{REFERENCES}

Arora, R., L.J. Rowland and K. Tanino. 2003. Induction and release of bud dormancy in woody perennials: a science comes of age. Hort. 38: 911-921.

Berruti, A., V. Scariot, A. Christiaens, M.C. Van Labeke. 2012. Changes in ABA levels in vegetative and flower buds during dormancy in camellia. Acta Hort. 953: 247254.

Bodson, M. 1986. Effect of $\mathrm{GA}_{4+7}$ on the initiation and development of the inflorescence bud of evergreen azalea. Tree Physiol. 1: 95-99.

Bouchard, J. and R.L. Momparler. 1983. Incorporation of 5Aza-2'-Deoxycytidine-5'-Triphosphate into DNAInteractions with mammalian DNA polymerase-alpha and DNA methylase. Mol. Pharmacol. 24: 109-114.

Brown, J.C.L., M.M. De Decker and M.A. Fieldes. 2008. A comparative analysis of developmental profiles for DNA methylation in 5-azacytidine-induced earlyflowering flax lines and their control. Plant Sci. 175: 217-225.

Burn, J.E., D.J. Bagnall, J.D. Metzger, E.S. Dennis and W.J. Peacock. 1993. DNA Methylation, vernalization, and the initiation of flowering. Proc. Natl. Acad. Sci. 90: 287-291.

Chang, Y.S. and F.H. Sung. 2000. Effects of gibberellic acid and dormancy-breaking chemicals on flower development of Rhododendron pulchrum Sweet and $R$. scabrum Don. Sci. Hortic. 83: 331-337.

Christiaens, A., E. De Keyser, P. Lootens, E. Pauwels, I. Roldan-Ruiz, J. De Riek, B. Gobin and M.C. Van Labeke. 2015. Cold storage to overcome dormancy affects the carbohydrate status and photosynthetic capacity of Rhododendron simsii. Plant Biol. 17: 97105.

Christiaens, A., E. Dhooghe, D. Pinxteren and M.C. Van Labeke. 2012. Flower development and effects of a cold treatment and a supplemental gibberellic acid application on flowering of Helleborus niger and Helleborus x ericsmithii. Sci. Hortic. 136: 145-151.

Demeulemeester, M.A.C., N. Van Stallen and M.P. DeProft. 1999. Degree of DNA methylation in chicory (Cichorium intybus L.): influence of plant age and vernalization. Plant Sci. 142: 101-108.

Finnegan, E.J., R.K. Genger, W.J. Kovac, W.J. Peacock and E.S. Dennis. 1998. DNA methylation and the promotion 
of flowering by vernalization. Proc. Natl. Acad. Sci. 95: 5824-5829.

Gotz, K.P., F.M. Chmielewski, T. Homann, G. Huschek, P. Matzneller and H.M. Rawel. 2014. Seasonal changes of physiological parameters in sweet cherry (Prunus avium L.) buds. Sci. Hortic. 172: 183-190.

Hao, J.J., W.J. Yang and H.F. Han. 2001. Experimental Technology in Plant Physiology. Scientific Technol. Publ. House of Liaoning Province, Shenyang, China (in Chinese).

Jones, P.A. 1985. Altering gene expression with 5azacytidine. Cell 40: 485-486.

Kondo, H., H. Ozaki, K. Itoh, A. Kato and K. Takeno. 2006. Flowering induced by 5-azacytidine, a DNA demethylating reagent in a short-day plant, Perilla frutescens var. crispa. Physiol. Plant. 127: 130-137.

Kondo, H., T. Miura, K.C. Wada and K. Takeno. 2007. Induction of flowering by 5-azacytidine in some plant species: relationship between the stability of photoperiodically induced flowering and flowerinducing effect of DNA demethylation. Physiol. Plant. 131: 462-469.

Kondo, H., T. Shiraya, K.C. Wada and K. Takeno. 2010. Induction of flowering by DNA demethylation in Perilla frutescens and Silene armeria: Heritability of 5azacytidine-induced effects and alteration of the DNA methylation state by photoperiodic conditions. Plant Sci. 178: 321-326.

Lizal, P. and J. Relichova. 2001. The effect of day length, vernalization and DNA demethylation on the flowering time in Arabidopsis thaliana. Physiol. Plant. 113: 121127.

Meijon, M., I. Feito, L. Valledor, R. Rodriguez and M.J. Canal. 2010. Dynamics of DNA methylation and Histone $\mathrm{H} 4$ acetylation during floral bud differentiation in azalea. BMC Plant Biol. 10: 10.
Meijon, M., I. Feito, L. Valledor, R. Rodriguez and M.J. Canala. 2011. Promotion of flowering in azaleas by manipulating photoperiod and temperature induces epigenetic alterations during floral transition. Physiol. Plant. 143: 82-92.

Meijon, M., L. Valledor, M.E. Santamaria, P.S. Testillano, M.C. Risueno, R. Rodriguez, I. Feito and M.J. Canal. 2009. Epigenetic characterization of the vegetative and floral stages of azalea buds: dynamics of DNA methylation and histone $\mathrm{H}_{4}$ acetylation. J. Plant Physiol. 166: 1624-1636.

Scariot, V., T. Handa and J. De Riek. 2007. A contribution to the classification of evergreen azalea cultivars located in the Lake Maggiore area (Italy) by means of AFLP markers. Euphytica 158: 47-66.

Wang, X.Y. 2014. Consumption of new year flower is switched to the terminal market. China Flow. Hort. 1: 10-13.

Yeo, S.M., Y.H. Rhie, S.Y. Lee, H.H. Jung and K.S. Kim. 2012. Dormancy release and flowering of Paeonia lactiflora 'Taebaek' by natural cumulative chilling and $\mathrm{GA}_{3}$ treatment. Hort. Environ. Biotechnol. 53 : 263-270.

Zhou, H., J. Liao, Y.P. Xia and Y.W. Teng. 2013a. Morphological characteristics for classifying evergreen azalea (Ericaceae) cultivars in China using numerical taxonomy. Pak. J. Botany. 45 : 593-598.

Zhou, H., J. Liao, Y.P. Xia and Y.W. Teng. 2013b. Determination of genetic relationships between evergreen azalea cultivars in China using AFLP markers. Journal of Zhejiang Univ.-SCI. B. 14 : 299308.

Zhou, W.W. 2010. Current development of azalea industry in China. China Flow. \& Hort. Vol?? : 12-14. 